\title{
PENGUKURAN KINERJA SDM METODE HUMAN RESOURCES SCORECARD SEBAGAI UPAYA OPTIMALISASI KINERJA ORGANISASI
}

\author{
Dwi Ermayanti S \\ STIE PGRI DEWANTARAJOMBANG
}

\begin{abstract}
KSP Sejahtera Jatim is one of the cooperatives engaged in saving and loan. As a factor determines the attainment of the objectives of the company is employee performance. During this time, KSP Sejahtera Jatim has being improved the quality of human resources, only measuring soft skill employee performance and subjectively. The Company has never made the measurement of employee performance as a whole so it is unknown any factors have not been identified and has not been achieved in forming the better quality of employee performance. Human Resources Scorecard is a performance measurement system of human resource that linked person-strategy-performance to produce a superior company. Human Resources Scorecard describes vision, mission, and human resources strategy into action a measurable contribution. The measurement of human resources performance considering business units from four perspectives are financial perspective, customer perspective, internal business process perspective, learning and growth perspective. Each perspective within Scorecard Human resources method is applied by Analytical Hierarchy process method.
\end{abstract}

Keywords: Human Resources Scorecard method, Analytical Hierarchy Process method.

Dewasa ini, persaingan antar perusahaan yang sangat ketat membutuhkan kemampuan perusahaan untuk meningkatkan kinerja secara menyeluruh. Tiap perusahaan dituntut untuk meningkatkan performa kinerja secara menyeluruh dalam menghadapi kompetisi dan menggunakan sumber daya secara efektif dan efisien yang pada akhirnya visi, misi dan strategi perusahaan dapat tercapai.

Di dalam KSP Sejahtera ini masih belum terdapat suatu sistem pengukuran kinerja karyawan yang baku dan bersifat komprehensif atau menyeluruh, selama ini ukuran kinerja sumber daya manusia perusahaan lebih dititik beratkan hanya pada sisi administratifnya saja atau selama hari kerja karyawan tersebut sesuai dengan job description. Pimpinan perusahaan menganggap karyawan tersebut telah bekerja dengan baik tanpa ada kesalahan dan sesuai dengan prosedur yang berlaku pada perusahaan. Hal ini dapat menyebabkan perusahaan tidak berusaha untuk memperbaiki kinerja karyawannya dan tetap pada kondisi yang sama secara terus menerus. Berdasarkan kondisi perusahaan maka perusahaan memerlukan suatu pengukuran kinerja sumber daya manusia dengan menggunakna konsep Human Resources Scorecard (HRSC) dalam memperbaiki dan meningkatkan kinerja sumber daya manusia dalam suatu perusahaan. Konsep pengukuran ini sangat penting bagi perusahaan agar dapat secara efektif mengolah tanggung jawab yang strategic untuk menghadapi persaingan dimasa mendatang sehingga tercapai visi dan misi perusahaan. Adapun tujuan dari penelitian adalah melakukan pengukuran kinerja sumber daya manusia dengan menggunakan metode Human Resources Scorecard dan mengetahui manfaat menggunakan metode Human Resources Scorecard pada KSP Sejahtera Jatim.

\section{Sumber Daya Manusia}

Menurut Dessler (2006,p4) manajemen sumber daya manusia adalah proses memperoleh, melatih, nilai dan memberikan kompensasi kepada karyawan, memperhatikan hubungan kerja mereka, kesehatan dan keamanan, serta masalah keadilan, L.Byars dan W. Rue (2005,p4) manajemen sumber daya manusia adalah suatu aktifitas yang di desain untuk menyediakan dan mengkoordinasikan sumber daya manusia pada suatu organisasi dan Noe/Hollenbeck/Gerhart/ Wright (2008,p2) manajemen sumber daya manusia adalah kebijakan, pelatihan, dan sistem yang mempengaruhi perilaku karyawan, sikap, dan performance.

\section{Manajemen Sumber Daya Manusia yang Strategis \\ Brian E. Becker dalam buku'The Human Re- sotirces Scorecard, Linking People, Strategy, and Performance' mengemukakan 4 perspektif tentang evolusi sumber daya manusia sebagai aset strategik.}


Evolusi sumber daya manusia sebagai aset strategik sebagai berikut: a) The personel perspective, yaitu perusahaan merekrut karyawan yang paling baik dan mengembangkannya. b) The compensation perspectives, yaitu perusahaan menggunakan bonus, embayaran insentif, dan perbedaan-perbedaan yang berarti dalam embayaran untuk memberi ganjaran kepada karyawan yang berprestasi tinggi dan endah. c) The alignment perspective, yaitu manajer senior melihat karyawan sebagai set strategik namun mereka tidak melakukan investasi dalam meningkatkan kapabititas sumber daya manusia. d) The high performance perspective, yaitu eksekutif sumber daya manusia dan yang lain memandang sumber daya sebagai suatu sistem yang melekat dalam sistem yang tebih besar dari implementasi strategi perusahaan.

\section{Kinerja}

Menurut Moeheriono (2012:95) pengertian kinerja atau performance merupakan gambaran mengenai tingkat pencapaian pelaksanaan suatu program kegiatan atau kebijakan dalam mewujudkan sasaran, tujuan, visi dan misi organisasi yang dituangkan melalui perencanaan strategis suatu organisasi. Menurut Rivai dkk (2009:604) Kinerja adalah suatu istilah secara umum yang digunakan untuk sebagian atau seluruh tindakan atau aktivitas dari suatu organisasi pada suatu periode dengan referensi pada sejumlah standar

\section{Indikator Kinerja Karyawan}

Penentuan Indikator Kinerja menurut Moeheriono (2012:113) adalah sebagai berikut: Efektif, Efisien, Kualitas, Ketepatan waktu, Produktivitas dan Keselamatan. Indikator ini mengukur kesehatan organisasi secara keseluruhan serta lingkungan kerja para pegawainya ditinjau dari aspek keselamatan.

\section{Human Resource Scorecard}

Menurut Brian E. Becker, Mark A Huselid \& Dave Ulrich (2009,pxii) human resource scorecard adalah kapasitas untuk merancang dan menerapkan sistem pengukuran SDM yang strategis dengan merepresentasikan "alat pengungkit yang penting" yang digunakan perusahaan untuk merancang dan mengerahkan strategi SDM yang lebih efektif secara cermat. Menurut Gary Desler (2006,p16) human resource scorecard adalah mengukur keefektifan dan efisiensi fungsi human resource dalam membentuk perilaku karyawan yang dibutuhkan untuk mecapai tujuan strategis perusahaan.

\section{HR Scorecard sebagai Model Pengukuran Kinerja Sumber Daya Manusia}

Menurut Becker, et al. (2001), dasar dari peran sumber daya manusia yang strategis terdiri dari tiga dimensi rantai nilai (value chain) yang dikembangkan oleh arsitektur sumber daya manusia perusahaan, yaitu fungsi, sistem dan perilaku karyawan.

\section{Metode Human Resources Scorecard (HRSC)}

Metode Human Resources Scorecard sangat bermanfaat dalam memahami perbedaan antara Human Resources Doables (Kinerja SDM yang tidak mempengaruhi implementasi strategi perusahaan) dengan Human Resources Deliverable (Kinerja SDM yang mempengaruhi implementasi strategi perusahaan). Tolak Ukur Rivai dkk (2009:612) menjelaskan perspektif yang harus diperhatikan dalam pengukuran kinerja selain perspektif keuangan, paling tidak ada tiga perspektif lain yang juga harus mendapatkan perhatian yakni pelanggan, proses bisnis internal dan pembelajaran dan pertumbuhan.

\section{Kerangka Konseptual}

Kerangka konseptual dari penelitian ini adalah sebagaimana gambar 1 .

\section{Metode}

Penelitian ini adalah jenis penelitian deskriptif kuantitatif. Penelitian ini dilakukan dalam tiga tahap yaitu survey pendahuluan, pengumpulan data, dan analisis pada tabel 1 ..

Populasi yang digunakan dalam penelitian ini adalah seluruh karyawan KSP Sejahtera Jatim yang berjumlah 50 orang karyawan. Sumber daya manusia yang ada di KSP Sejahtera meliputi beberapa bagian yaitu Manajer,accounting, administrasi penjualan, penagihan. Sampel dari jumlah sampel tersebut terdiri dari manajer, accounting, bagian penjualan, kasir, dan bagian penagihan.

Teknik pengumpulan data yang digunakan dalam penelitian ini adalah sebagai berikut: Wawancara dan Kuesioner

Pengolahan Data, Pengolahan data meliputi kegiatan sebagai berikut: Editing, Codeting (Pengkodean), Tabulasi dan Pemberian skor atau nilai. 
Pengukuran Kinerja Sdm Metode Human Resources Scorecard

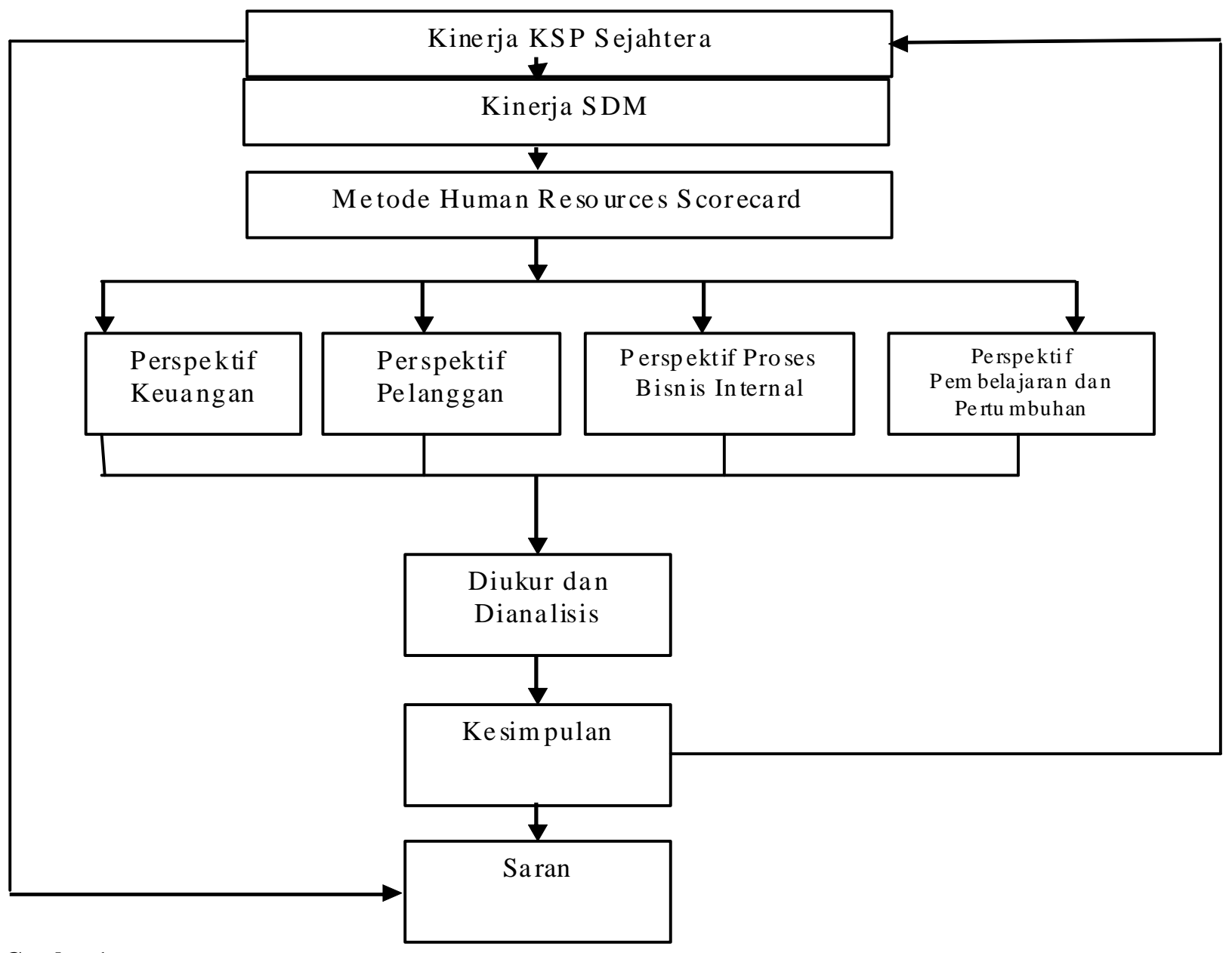

Gambar 1.

Tabel 1. Variabel, Indikator, dan Skala Pengukuran Kinerja Organisasi

\begin{tabular}{|c|c|c|c|c|}
\hline Perspektif & Indikat or & Sub Indikator & $\begin{array}{c}\text { Skala } \\
\text { Pengukuran }\end{array}$ & Instrumen \\
\hline \multirow[b]{2}{*}{ Financial } & $\begin{array}{l}\text { F1.Meningkatkan } \\
\text { Produktivitas } \\
\text { Karyawan }\end{array}$ & F1a.Revenue per karyawan & Ordinal & Kuesioner \\
\hline & $\begin{array}{l}\text { Karyawan } \\
\text { F2.Meningkatkan } \\
\text { Efisiensi di lini } \\
\text { SDM }\end{array}$ & $\begin{array}{l}\text { F2a.prosentase penurunan } \\
\text { biaya pengelolaan SDM }\end{array}$ & Ordinal & Kuesioner \\
\hline \multirow{4}{*}{ Customer } & $\begin{array}{l}\text { C1.meningkatkan } \\
\text { Customer }\end{array}$ & $\begin{array}{l}\text { C1a.Prosentase jumlah } \\
\text { komplain yang } \\
\text { terselesaikan }\end{array}$ & Ordinal & Kuesioner \\
\hline & Satisfaction & $\begin{array}{l}\text { C1b.Jumlah complain } \\
\text { yang masuk. }\end{array}$ & Ordinal & Kuesioner \\
\hline & $\begin{array}{l}\text { C2.Meningkatkan } \\
\text { Customer Service }\end{array}$ & $\begin{array}{l}\text { C2a.Prosentase Ontime } \\
\text { Service }\end{array}$ & Ordinal & Kuesioner \\
\hline & $\begin{array}{l}\text { I1 Employee } \\
\text { Satisfaction }\end{array}$ & Ila.Indeks kepuasan kerja & Ordinal & Kuesioner \\
\hline \multirow{2}{*}{$\begin{array}{l}\text { Internal } \\
\text { Business } \\
\text { Process }\end{array}$} & $\begin{array}{l}\text { I2.Meningkatkan } \\
\text { kecepatan layanan } \\
\text { bagi karyawan }\end{array}$ & $\begin{array}{l}\text { I2a.rata-rata waktu proses } \\
\text { pengeluaran surat ijin } \\
\text { dinas luar }\end{array}$ & Ordinal & Kuesioner \\
\hline & $\begin{array}{l}\text { I3.pemberian } \\
\text { kesejahteraan yang } \\
\text { tepat }\end{array}$ & $\begin{array}{l}\text { I3a.prosentase jumlah } \\
\text { karyawan yang mengikuti } \\
\text { persiapan pension }\end{array}$ & Ordinal & Kuesioner \\
\hline
\end{tabular}




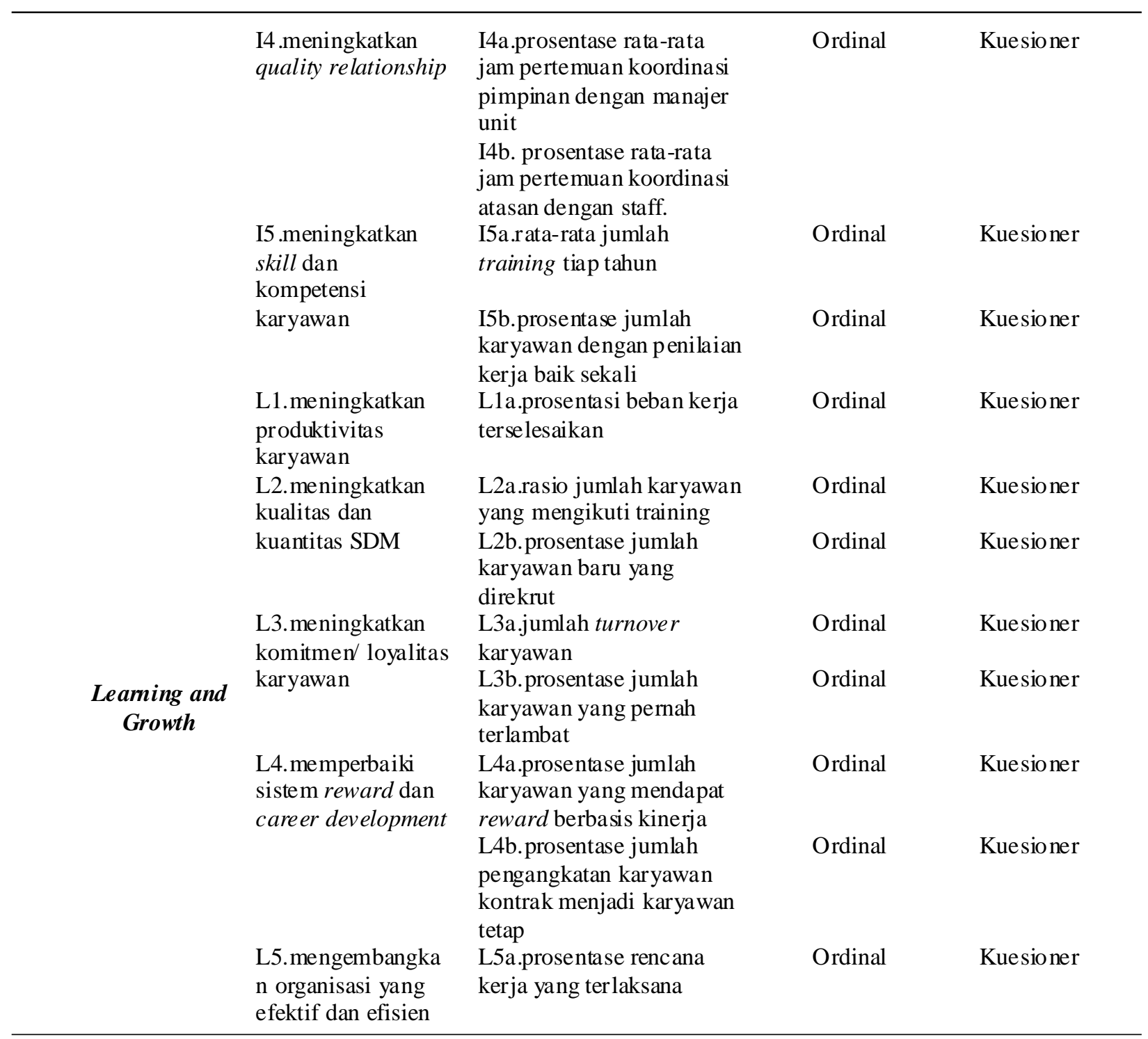

Tabel 2. Skala Penilaian

\begin{tabular}{cl}
\hline Nilai & \multicolumn{1}{c}{ Keterangan } \\
\hline 7 & A sangat jauh lebih disukai dari B \\
6 & A jauh lebih disukai dari B \\
5 & A sedikit lebih disukai dari B \\
4 & A sama dengan B \\
3 & A sedikit kurang disukai dari B \\
2 & A jauh kurang disukai dari B \\
1 & A sangat jauh kurang disukai dari B \\
\hline
\end{tabular}

Uji Menggunakan Metode Analitycal Hierarchy Process (AHP)

Secara garis besar ada 3 tahapan AHP dalam penyusunan prioritas yaitu:

1. Dekomposisi dari masalah

2. Penilaian untuk membandingkan elemenelemen hasil dekomposisi
Dari tabel 3 tersebut dapat dirangkum seperti tabel berikut ini:

1. CR(i) merupakan hasil penilaian /perbandingan antar kriteria

2. $\mathrm{C}(\mathrm{n})$ merupakan penjumlahan dari criteria ke (i)

3. C merupakan penjumlahan dari semua nilai $\mathrm{Cn}$

4. Bobot kriteria ke (i) diperoleh dengan membagi nilai C(i) dengan $\mathrm{C}$

Dengan menggunakan prosedur yang sama, maka dilakukan perbandingan antar pilihan $(\mathrm{OP})$ untuk masing-masing kriteria. Tabel berikut ini akan mengilustrasikan perbandingan antar pilihan (4 pilihan) untuk kriteria $1(\mathrm{C} 1)$ sebagai berikut : $\mathrm{O}(\mathrm{n})$ merupakan hasil penilaian atau pembandingan antara pilihan (i). dengan $\mathrm{k}$ untuk kriteria ke j, O(i) merupakan penjumlahan nilai yang dimiliki pilihan ke(i), O merupakan penjumlahan semua nilai $\mathrm{O}$ dan $\mathrm{Bo}(\mathrm{n})$ merupakan nilai pilihan ke (i) untuk kriteria ke j. 


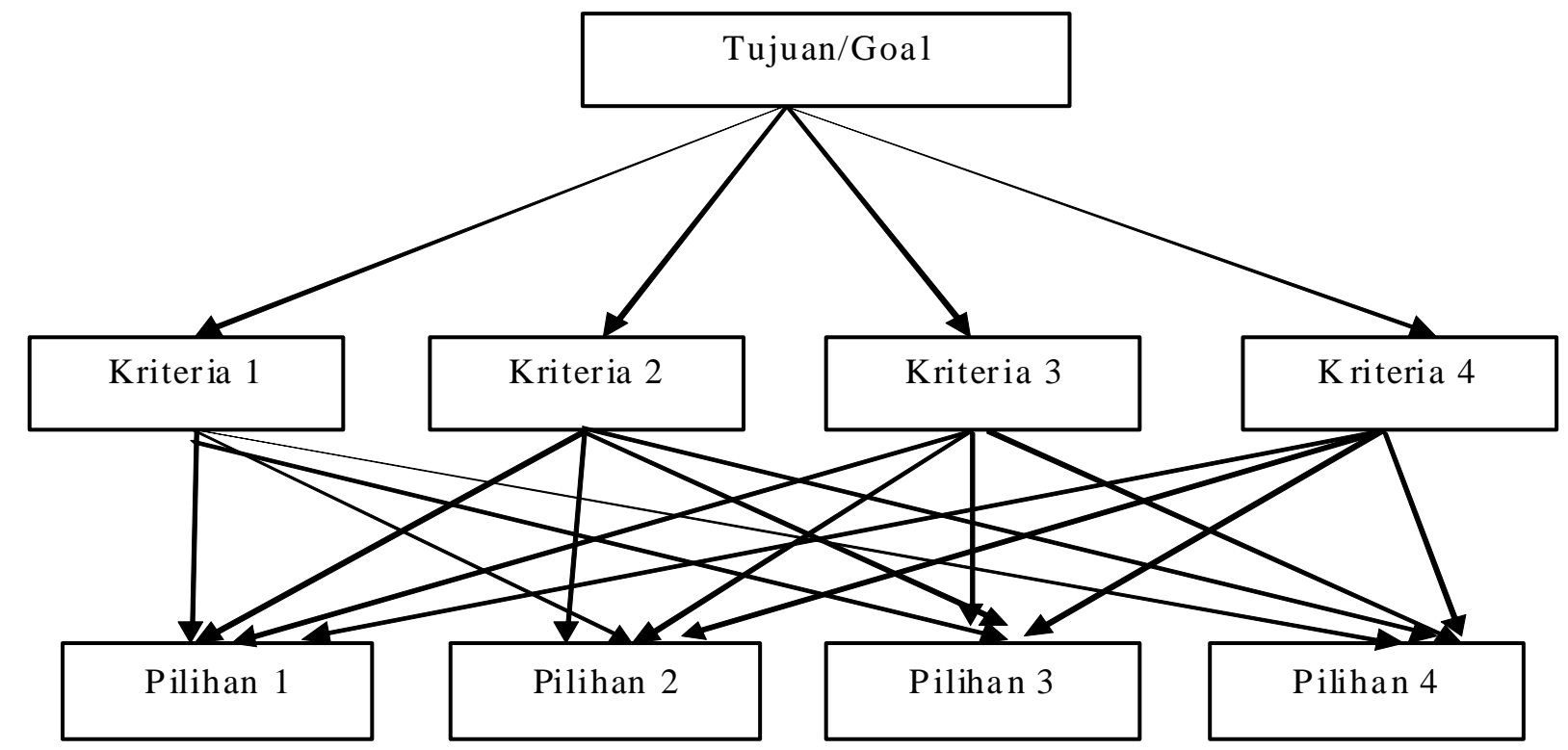

Gambar 2. Dekomposisi Masalah

Tabel 3. Skala Penilaian

\begin{tabular}{lcc}
\hline \multicolumn{1}{c}{ Hasil Penilaian } & Nilai A & Nilai B \\
\hline A sangat jauh lebih disukai dari B & 1,9 & 0,1 \\
A jauh lebih disukai dari B & 1,6 & 0,4 \\
A sedikit lebih disukai dari B & 1,3 & 0,7 \\
A sama dengan B & 1,0 & 1,0 \\
A sedikit kurang disukai dari B & 0,7 & 1,3 \\
A jauh kurang disukai dari B & 0,4 & 1,6 \\
A sangat jauh kurang disukai dari B & 0,1 & 1,9 \\
\hline
\end{tabular}

Sumber: Bourgeois (2005)

Tabel 4. Perbandingan antar kriteria

\begin{tabular}{ccccccc}
\hline Kriteria & CR1 & CR2 & CR3 & CR4 & Jumlah & Bobot \\
\hline CR1 & - & CR12 & CR13 & CR14 & C1 & bc1 = C1/C \\
CR2 & CR21 & - & CR23 & CR24 & C2 & bc1= C2/C \\
CR3 & CR31 & CR32 & - & CR34 & C3 & bc1 = C3/C \\
CR4 & CR41 & CR42 & CR43 & - & C4 & bc1 = C4/C \\
\hline Jumlah & & & & & C & \\
\hline
\end{tabular}

Tabel 5. Perbandingan atar pilihan untuk kriteria ke C1

\begin{tabular}{ccccccc}
\hline C1 & OP1 & OP2 & OP3 & OP4 & Jumlah & Bobot \\
\hline OP1 & - & O12 & O13 & O14 & O1 & BO11= O1/O \\
OP2 & O21 & - & O23 & O24 & O2 & BO21= O2/O \\
OP3 & O31 & O32 & - & O34 & O3 & BO33= O3/O \\
OP4 & O41 & O42 & O43 & - & O4 & BO44= O4/O \\
\hline Jumlah & & & & & O & \\
\hline
\end{tabular}

\section{Sintesis Penilaian}

Sintesis hasil penilaian merupakan tahap akhir dari AHP. Pada dasarnya sintesis ini merupakan penjumlahan dari bobot yang diperoleh setiap pilihan pada masing-masing kriteria setelah diberi bobot dari kriteria tersebut. Secara umum nilai suatu pilihan adalah sebagai berikut:

bop $i=\sum_{i=1}^{n}$ bo $n * b c j$

Bop $i=$ nilai/bobot untuk pilihan ke $\mathrm{i}$ 
Dwi Ermayanti S

Tabel 6. Sintesa penilaian

\begin{tabular}{llllll}
\hline & CR1 & CR2 & CR3 & CR4 & Prioritas \\
\hline & bc1 & bc2 & bc3 & bc4 & bopi \\
OP1 & bo11 & bo12 & bo13 & bo14 & bop1 \\
OP2 & bo21 & bo22 & bo23 & bo24 & bop2 \\
OP3 & bo31 & bo32 & bo33 & bo34 & bop3 \\
OP4 & bo41 & bo42 & bo43 & bo44 & bop4 \\
\hline
\end{tabular}

\section{Uji Konsistensi}

Pengukuran konsistensi dari suatu matriks itu sendiri didasarkan atas eigen value maksimum. Thomas L Saaty telah membuktikan bahwa indeks konsistensi dari matriks berordo $n$ dapat diperoleh dengan rumus sebagai berikut:

$C I=\frac{(\partial \max -\mathrm{n})}{(\mathrm{n}-1)}$

Hasil dan Pembahasan

Tabel 7. Hasil Pengujian Validitas

\begin{tabular}{|c|c|c|c|c|}
\hline No & Variable / it em & r hitung & $\mathbf{r}$ table & Ket erangan \\
\hline \multicolumn{5}{|c|}{ Financial $(\mathrm{F})$} \\
\hline 1 & 1 & 0.813 & 0,279 & valid \\
\hline 2 & 2 & 0.786 & 0,279 & valid \\
\hline \multicolumn{5}{|c|}{ Customer $(C)$} \\
\hline 3 & 1 & 0.828 & 0,279 & valid \\
\hline 4 & 2 & 0.814 & 0,279 & valid \\
\hline 5 & 3 & 0.815 & 0,279 & valid \\
\hline \multicolumn{5}{|c|}{ Internal Business Process (I) } \\
\hline 6 & 1 & 0.367 & 0,279 & valid \\
\hline 7 & 2 & 0.615 & 0,279 & valid \\
\hline 8 & 3 & 0.650 & 0,279 & valid \\
\hline 9 & 4 & 0.664 & 0,279 & valid \\
\hline 10 & 5 & 0.787 & 0,279 & valid \\
\hline 11 & 6 & 0.673 & 0,279 & valid \\
\hline \multicolumn{5}{|c|}{ Learning and Growth $(L)$} \\
\hline 12 & 1 & 0.308 & 0,279 & valid \\
\hline 13 & 2 & 0.782 & 0,279 & valid \\
\hline 14 & 3 & 0.620 & 0,279 & valid \\
\hline 15 & 4 & 0.675 & 0,279 & valid \\
\hline 16 & 5 & 0.727 & 0,279 & valid \\
\hline 17 & 6 & 0.757 & 0,279 & valid \\
\hline 18 & 7 & 0.587 & 0,279 & valid \\
\hline 19 & 8 & 0.586 & 0,279 & valid \\
\hline
\end{tabular}




\section{Uji Reliabilitas}

Tabel 8. Hasil Pengujian Reliabilitas

\begin{tabular}{ccc}
\hline Variabel & $\begin{array}{c}\text { Nilai hitung Alpha } \\
\text { Cronbach }\end{array}$ & Keterangan \\
\hline Pengukuran Kinerja Karyawan (X) & 0,875 & Reliabel \\
Nilai dari Optimalisasi Kinerja Karyawan (Y) & 0,837 & Reliabel \\
\hline
\end{tabular}

Conclusion, Implication and Limitation

Tabel 9. Hasil Penelitian Perbandingan antar kriteria

\begin{tabular}{lrrrrr}
\hline Kriteria & F & \multicolumn{1}{c}{ C } & \multicolumn{1}{c}{ I } & \multicolumn{1}{l}{ L } & \multicolumn{1}{c}{ Total } \\
\hline F & 0 & 0,153 & 0,713 & 0,154 & 0,492 \\
C & 0,153 & 0 & 0,69 & 0,842 & 0,883 \\
I & 0,713 & 0,69 & 0 & 0,623 & 0,893 \\
L & 0,154 & 0,842 & 0,623 & 0 & 0,899 \\
\hline Total & $\mathbf{1 , 0 2}$ & $\mathbf{1 , 6 8 5}$ & $\mathbf{2 , 0 2 6}$ & $\mathbf{1 , 6 1 9}$ & $\mathbf{3 , 1 6 7}$ \\
\hline
\end{tabular}

\section{KESIMPULAN DAN SARAN}

\section{Kesimpulan}

Berdasarkan hasil analisis dan pembahasan yang telah dilakukan pada bab sebelumnya maka pengukuran kinerja sumber daya manusia dengan menggunakan metode Human Resources Scorecard diperoleh simpulan sebagai berikut: Pertama, perspektif learning and growth $(L)$ dengan skor 0,899, perspektif ini harus dijadikan prioritas pertama. Untuk meningkatkan perspektif ini dilakukan dengan cara sebagai berikut: meningkatkan produktivitas karyawan meningkatkan kualitas dan kuantitas sumber daya manusia, Meningkatkan komitmen/loyalitas karyawan, Memperbaiki sistem reward dan career development. Mengembangkan organisasi yang efektif dan efisien. Kedua, perspektif internal business process (I) dengan skor 0,893 . Prioritas ini mendapatkan kedudukan kedua. Cara yang dilakukan untuk meningkatkan perspektif ini dengan cara melakukan perbaikan pada employee satisfaction, meningkatkan kecepatan layanan bagi karyawan, pemberian kesejahteraan yang tepat, meningkatkan quality relationship dan meningkatkan skill dan kompetensi karyawan. Ketiga, perspektif customer dengan skor 0,883 menduduki peringkat ketiga. Cara yang dilakukan untuk mengoptimalkan melalui meningkatkan customer satisfaction dan meningkatkan customer service dan prioritas. Keempat, perspektif financial dengan skor 0,492. Cara yang dilakukan untuk mengoptimalkan adalah memperbaiki dan meningkatkan produktivitas karyawan dan meningkatkan efisiensi di lini sdm.

\section{Saran}

Perspektif Learning and Growth $(L)$ untuk meningkatkan perspektif ini dilakukan dengan cara sebagai berikut: meningkatkan produktivitas karyawan meningkatkan kualitas dan kuantitas sumber daya manusia, meningkatkan komitmen/loyalitas karyawan, memperbaiki sistem reward dan career development dan mengembangkan organisasi yang efektif dan efisien

Perspektif Internal Business Process (I). Cara yang dilakukan untuk meningkatkan perspektif ini dengan cara: Melakukan perbaikan pada Employee Satisfaction, Meningkatkan kecepatan layanan bagi karyawan, Pemberian kesejahteraan yang tepat, Meningkatkan quality relationship dan Meningkatkan skill dan kompetensi karyawan.

Perspektif Customer. Cara yang dilakukan untuk mengoptimalkan: Meningkatkan Customer Satisfaction dan Meningkatkan Customer Service dan prioritas

Perspektif Financial. Cara yang dilakukan untuk mengoptimalkan adalah: Memperbaiki dan meningkatkan Produktivitas Karyawan dan Meningkatkan Efisiensi di lini SDM.

\section{DAFTAR RUJUKAN}

Arikunto. 2010. Prosedur Penelitian Suatu Pendekatan Praktik. Jakarta: Rineka Cipta.

Astuti, K.R. 2011. Lokakarya (Workshop) Human Resource Scorecard untuk Meningkatkan Persepsi Keterlibatan Kerja Karyawan Departemen Sumber Daya Manusia, 
Tesis Program Studi Psikologi Universitas Gajah Mada (tidak dipublikasikan).

Bourgeois, R. 2005. Analytical Hierarchy Process: an Overvie, UNCAPSA-UNESCA. Bogor.

Dessler. 2005. 'Definisi Human Resource Scorecard," http:// thesis.binus.ac.id/Doc/Bab2Doc/2011-2-00112N\%20Bab2001.doc. (diakses pada tanggal 12 Februari 2011)

Dharma, S., dan Sunatrio, Y. 2002. "Human Resource Scorecard, Dalam Paradigma Baru MSDM”, Editor: A. Usmara. Jakarta: Asmara Books.

Dumitrana, M., Gabriel, R., Mariana, E.G., dan Gabriel, J., 2011, "Effective and Efficient Tools in Human Resources Management Control", Petroleum-Gas University of Ploiesti Bulletin, Vol. LXIII, No. 3, pp. 5966.

H.Djaali and Muljono, Pudji. 2007. Pengukuran dalam bidang pendidikan. Jakarta: Grasindo.

Hursman. 2010. "Human Resources Key Performance Indicators," http://www.cjournal.cz/files/89.pdf . (diakses pada tanggal 10 Februari 2012).

Iveta, G. 2012. "Human Resources Key Performance Indicators", Journal of Competitiveness, Vol. 4, Issue 1, pp. 117-128.

L. Mathis Robert, Jackson H.J. 2005. Human Resources Management.

Luthfika, H.S. 2012. Analisis Pengukuran Kinerja Sumber Daya Manusia Menggunakan metode Human Resources Scorecard. Jurnal.

Mangkunegara, A.A., Anwar Prabu. 2005. Evaluasi Kinerja SDM. Bandung: Refika Aditama.
Moeheriono. 2012. Pengukuran Kinerja Berbasis Kompetensi. Jakarta: Raja Grafindo Persada.

Nilda, T.P., Insannul, K., dan Demi, R. 2012. ”Perancangan Standar Penilaian Kinerja Pemeliharaan Lampu Jalan Berdasarkan Key Performance Indiktors (KPI)(Studi Kasus di Kota Padang)", Jurnal Optimasi Sistem Industri, Vol. 11 No. 2, Oktober 2012:225-234.

Permadi, B. 1992. AHP. Pusat Antar Universitas, Universitas Indonesia. Jakarta.

Rivai,V., and Sagala, E.J. 2009. Manajemen Sumber Daya Manusia untuk Perusahaan. Jakarta: Raja Grafindo Persada.

Rivai, 2010 ," Langkah-Langkah Pendekatan Human Resource Score card," http://thesis.binus.ac.id/Doc/ Bab2Doc/2011 - 2 - 00112 - MN\%20Bab2001.doc . (diakses pada tanggal 12 Februari 2011).

Rusindiyanto. 2009," Analisis Kinerja Sumber Daya Manusia Dengan Metode Human Resource Scorecard (HRSC) (Studi Kasus Di PT. Arto Metal Internasional Sidoarjo “, Jurnal Penelitian Ilmu Teknik Vol.9, No.2 Desember 2009: 123-129.

Siregar, S. 2012. Metode Penelitian Kuantitaif dilengkapi dengan perbandingan perhitungan manuual dan SPSS. Jakarta: Kencana Prenada Media Group.

Saaty, L.T. 2005. Theory and applications of analytic network process: Decision making with benefits, opportunities, costs and risks. RWS Publication.

Sugiyono. 2009. Metode Penelitian Kuantitatif,kualitatif dan $R \& D$. Bandung: Alfabeta.

Yos, I.M., Harmein, N., dan Aulia, I. 2013. 'Evaluasi Kinerja Manajemen Sumber Daya Manusia PT. Bank XYZ Dengan Human Resource Scorecard," Jurnal Teknik Industri FT USU Vol 1, No.1, Januari 2013 pp. 23-27. 